\title{
Applicability Evaluation for Reference Crop Evapotranspiration in Hebei Provence
}

\author{
Xingxing Long ${ }^{1, a}$, Luhua Yang ${ }^{2, b}$, Hui Xia ${ }^{1, c}$, Linxuan Huo ${ }^{1, d}$, Wenchao Ma ${ }^{3, e}$, \\ Yakun $\operatorname{Han}^{1, f}$ \\ ${ }^{1}$ Agricultural University of Hebei, Hebei Baoding \\ ${ }^{2}$ Tianjin Agricultural University, Tianjin \\ ${ }^{3}$ Hebei Engineering and Technical College, Hebei Cangzhou \\ a15933969077@163.com; 'bangluhua@126.com; 'xiahui1106@163.com; \\ d15733226039@163.com; '904533445@qq.com ${ }^{\dagger} 411790119 @ q q . c o m$
}

\begin{abstract}
Keywords: Hebei Provence; Reference crop Evapotranspiration; Penman-Monteith equation; Applicability evaluation; scoring method

Abstract: Based on 53 years of daily meteorological data from 1961 to 2013 provided by 19 meteorological stations in Hebei Provence, seven algorithms of Penman-Monteith (P-M), Hargreaves-Samani (H-S), Irmark-Allen (I-A), Pristley-Taylor (P-T), Makkink (M-K), Penman-Van Bavel (PVB), 1948 Penman(48-PM) were used to calculate daily ET 0 of 3 areas in Hebei Provence. $\mathrm{P}-\mathrm{M}$ was used as a standard to be compared with other 6 algorithms for estimating $\mathrm{ET}_{0}$. The 6 algorithms were compared from the goodness-of-fit, definition and the applicability of monthly average $\mathrm{ET}_{0}$ accumulated values. The algorithms got its scores after each comparative respects. The results show: I-A did the best work, scoring 23 points, and 48-PM ranked second, 11 points; these 2 methods can be the simplified recommendation to calculate $\mathrm{ET}_{0}$ in Hebei Provence. The study proves that it is reasonable to value the applicability of each equation by the scoring method.
\end{abstract}

\section{Introduction}

The key to determine the water consumption of agriculture is to calculate reference crop evapotranspiration $\left(\mathrm{ET}_{0}\right)$, whose accuracy influences directly the irrigation program of crops, the reasonability of irrigation plans ${ }^{[1]}$, and the whole water requirement of agriculture. $\mathrm{ET}_{0}$ is also one of the most essential index to express the evaporation ability of atmosphere, evaluate the degree of climate drought, the water consumption of vegetation, potential productivity and the supply and demand balance of water resources ${ }^{[2,3]}$. The ways to calculate $\mathrm{ET}_{0}$ can be divided into 3 sorts: synthesis method, temperature method and radiation method ${ }^{[4]}$. The scholars made many studies about this field with different methods in different regions. Xystrakis ${ }^{[5]}$ analyzed the applicability of $13 \mathrm{ET}_{0}$ algorithms in Crete Island finding that Turc and Hansen method were more accurate. Azhar and Perera ${ }^{[6]}$ analyzed the applicability of $10 \mathrm{ET}_{0}$ algorithms in the southeast of Austrilia finding that compared with the measured value, P-M method existed 21\% 29\% errors, Hargreaves method'errors was 18\% 31\%; Qingyu Sun and someone else ${ }^{[7]}$ used 5 algorithms with the P-M method for standard finding that there were 9 parts (among 10 parts) more close to the results calculated by Hargreaves algorithm and FAO-24 Radiation algorithm. $\mathrm{Zhi} \mathrm{Li}^{[8]}$ also used 6 ways to calculate the applicability of loess plateau finding FAO-24 BC and Hargreaves method were better than others.

Many scholars study the applicability of different $\mathrm{ET}_{0}$ algorithms in different regions from various evaluation aspects, but the results of each aspect usually goes to different conclusion. So it is common to summarize the study based on qualitative analysis. In this paper, based on 19 meteorological stations provided 53 years of daily meteorological data from 1961 to 2013 of Hebei Provence, 6 methods with P-M for standard were used to calculate daily $\mathrm{ET}_{0}$ of 3 partitions, and then each method was marked from 3 evaluation aspects. In the study, some tries were made to evaluate the characteristics in quantitative analysis by scoring, and proved that it was reasonable. 


\section{Materials and Method}

Study area.The study was conducted in Hebei Provence $\left(36^{\circ} \quad 01^{\prime} \mathrm{N} \sim 42^{\circ} \quad 37^{\prime} \mathrm{N}, 113^{\circ} \quad 04^{\prime} \mathrm{E} \sim 119^{\circ}\right.$ $\left.53^{\prime} \mathrm{E}\right)$ in the north of the North China Plain, dominated by cropland, mainly wheat and maize. The coastline of Hebei Provence is $487 \mathrm{~km}$, and the area is $187700 \mathrm{~km}^{2}$.Mean annual evaporation exceeds $565.2 \mathrm{~mm}$, and annual mean air temperature is $13.3^{\circ} \mathrm{C}$. The terrain slopes from north west to south east. Due to the influence of terrain to $\mathrm{ET}_{0}$, divide Hebei Provence into 3 part based on its altitude and latitude. The region where its altitude is lower than $200 \mathrm{~m}$ belongs to Plain area, between $200 \mathrm{~m}$ and $600 \mathrm{~m}$ belongs to Hilly area, and above $600 \mathrm{~m}$ belongs to Plateau area. These 3 divisions were named Part 1, Part 2 and Part 3 in turn, shown in Figure 1.

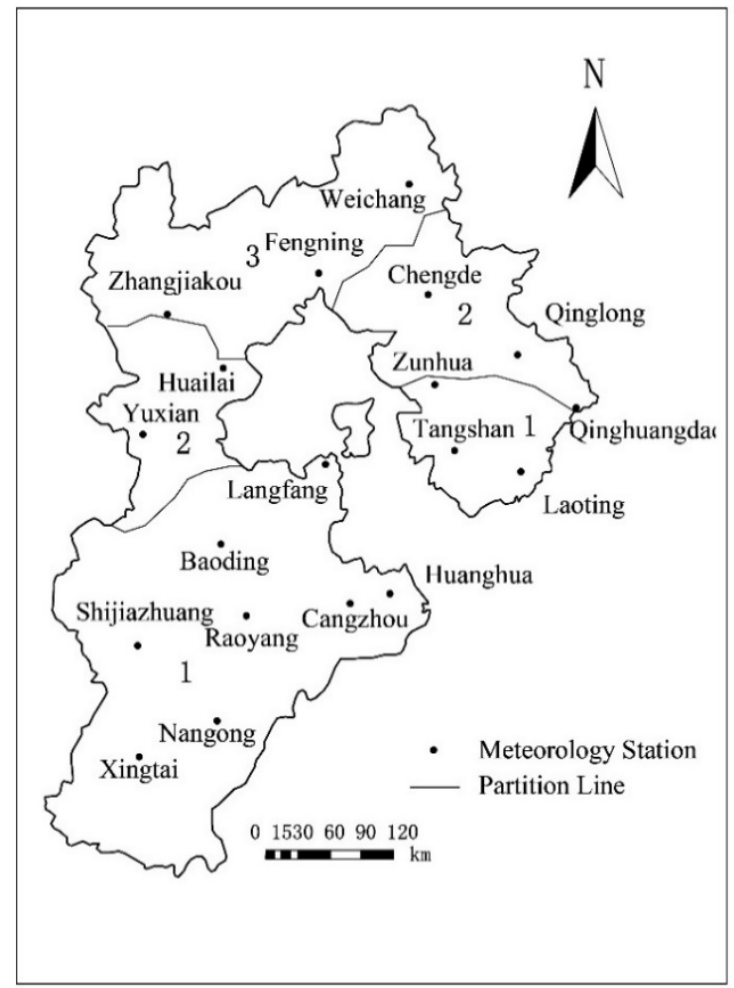

Fig.1 Area division and stations distribution in Hebei Provence

Data Materials. The daily meteorology data from 1961 to 2013 form 19 meteorology stations in Hebei Provence were provided by National Meteorological Information Center. The missing daily data was replenished by linear interpolation method. The daily meteorology data includes daily maximum temperature, daily minimum temperature, daily average temperature, average relative humidity, sunshine time, wind speed at $2 \mathrm{~m}$ height (calculated by $\mathrm{U}_{10}$ ). The information and distribution of 19 meteorology stations was showed in Figure 1.

\section{Study Method}

Expressions of Methods.Penman-Monteith method, 1998, is based on energy balance and aerodynamics, and its equation can be expressed as ${ }^{[7]}$ :

$$
E T_{0-P M}=\frac{0.408 \Delta\left(R_{n}-G\right)+\gamma \frac{900}{T+273} U_{2}\left(e_{s}-e_{a}\right)}{\Delta+\gamma\left(1+0.34 U_{2}\right)}
$$

Where, $\mathrm{ET}_{0-\mathrm{PM}}$, daily $\mathrm{ET}_{0}$ calculated by $\mathrm{P}-\mathrm{M} \operatorname{method}(\mathrm{mm} / \mathrm{d}) ; \Delta$, the slope of the saturation vapour pressure temperature relationship $\left(\mathrm{kPa} /{ }^{\circ} \mathrm{C}\right) ; \mathrm{R}_{\mathrm{n}}$, the net radiation $\left(\mathrm{MJ} \cdot \mathrm{m}^{-2} \cdot \mathrm{d}^{-1}\right) ; \mathrm{G}$, the soil heat flux represents the vapour pressure deficit of the $\operatorname{air}\left(\mathrm{MJ} \cdot \mathrm{m}^{-2} \cdot \mathrm{d}^{-1}\right) ; \gamma$, the psychrometric constant $\left(\mathrm{kPa} /{ }^{\circ} \mathrm{C}\right)$; $\mathrm{T}$, the mean daily air temperature $\left({ }^{\circ} \mathrm{C}\right) ; \mathrm{U}_{2}$, the wind speed at $2 \mathrm{~m}$ height $(\mathrm{m} / \mathrm{s}) ; \mathrm{e}_{\mathrm{s}}$, the saturation vapour 
pressure $(\mathrm{kPa}) ; \mathrm{e}_{\mathrm{a}}$, the actual vapour pressure $(\mathrm{kPa})$.

Hargreaves-Samani method, 1950s, is based on the conditions of heat and radiation, and its equation can be expressed as ${ }^{[9]}$ :

$$
E T_{0-H S}=C_{0}\left(T_{\max }-T_{\min }\right)^{0.5}\left(T_{\text {mean }}+17.8\right) R_{a}
$$

Where, $\mathrm{ET}_{0-\mathrm{HS}}$, daily $\mathrm{ET}_{0}$ calculated by $\mathrm{H}-\mathrm{S} \operatorname{method}(\mathrm{mm} / \mathrm{d}) ; \mathrm{C}_{0}$, transformation coefficient, 0.0023 ; $\mathrm{T}_{\max }$, daily maximum temperature $\left({ }^{\circ} \mathrm{C}\right) ; \mathrm{T}_{\min }$, daily minimum temperature $\left({ }^{\circ} \mathrm{C}\right) ; \mathrm{T}_{\text {mean }}$, daily average temperature $\left({ }^{\circ} \mathrm{C}\right) ; \mathrm{R}_{\mathrm{a}}$, extraterrestrial radiation $\left(\mathrm{MJ} \cdot \mathrm{m}^{-2} \cdot \mathrm{d}^{-1}\right)$.

Irmark-Allen method, 2003, is based on the conditions of heat and the net radiation. This method is widely used in moist area, and its equation can be expressed as ${ }^{[7]}$ :

$$
E T_{0-I A}=0.489+0.289 R_{n}+0.023 T_{\text {mean }}
$$

Where, $\mathrm{ET}_{0-\mathrm{IA}}$, daily $\mathrm{ET}_{0}$ calculated by $\mathrm{I}-\mathrm{A} \operatorname{method}(\mathrm{mm} / \mathrm{d})$; the other parameters are same with formula (2).

Priestley-Taylor method, 1972, is based on evaporation balance and the information of wet lands. This method is also widely used in moist area, and its equation can be expressed as ${ }^{[10]}$ :

$$
E T_{0-P T}=\alpha \frac{\Delta}{\Delta+\gamma}\left(R_{n}-G\right)
$$

Where, $\mathrm{ET}_{0-\mathrm{PT}}$, daily $\mathrm{ET}_{0}$ calculated by $\mathrm{P}-\mathrm{T} \operatorname{method}(\mathrm{mm} / \mathrm{d}) ; \alpha$, experience coefficient, 1.26 ; the other parameters are same with formula (1).

Marrink method, 1957, is only based on the solar radiation, and it was proved to have good adaptability in cold area. And its equation can be expressed as ${ }^{[8]}$ :

$$
E T_{0-M K}=\frac{0.61}{2.45} \frac{\Delta}{\Delta+\gamma} R_{\mathrm{s}}-0.12
$$

Where, $\mathrm{ET}_{0-\mathrm{MK}}$, daily $\mathrm{ET}_{0}$ calculated by $\mathrm{M}-\mathrm{K} \operatorname{method}(\mathrm{mm} / \mathrm{d}) ; \mathrm{R}_{\mathrm{s}}$, solar radiation, $\mathrm{MJ} \cdot \mathrm{m}^{-2} \cdot \mathrm{d}^{-1}$; the other parameters are same with formula (1).

Penman method, 1948, is the simplify calculation of Penman-Monteith method with no horizontal transport of water vapor. Its equation can be expressed as ${ }^{[11]}$ :

$$
E T_{0-48 P M}=\frac{\Delta\left(R_{n}-G\right)+6.43 \gamma\left(1+0.536 U_{2}\right)\left(e_{s}-e_{a}\right)}{\lambda(\Delta+\gamma)}
$$

Where, $\mathrm{ET}_{0-48 \mathrm{PM}}$, daily $\mathrm{ET}_{0}$ calculated by $48-\mathrm{PM} \operatorname{method}(\mathrm{mm} / \mathrm{d}) ; \lambda$, latent heat of vaporization, 2.45 $\mathrm{MJ} / \mathrm{kg}$; the other parameters are same with formula (1).

Cornelius Van Bavel improved the experience coefficient of Penman method, and named the new algorithm Penman-Van bavel method. Its equation can be expressed as ${ }^{[12]}$ :

$$
\begin{aligned}
& E T_{0-P V B}=\frac{\frac{e p s \times R_{n}}{\lambda}+\frac{e_{s}-e_{a}}{r_{s}}}{e p s+1} \\
& \text { eps }=1.005 \times\left(0.920-0.002632 T_{\text {mean }}+0.003075 T_{\text {mean }}^{2}\right), r_{s}=\frac{80.8}{u_{2}+0.1}
\end{aligned}
$$

Where, $\mathrm{ET}_{0-\mathrm{PVB}}$, daily $\mathrm{ET}_{0}$ calculated by $\mathrm{PVB} \operatorname{method}(\mathrm{mm} / \mathrm{d}) ; \mathrm{T}_{\text {mean }}$ is same with formula $(2)$; the other parameters are same with formula (1).

\section{Assessments}

Goodness-of-fit was evaluated by comparing $\mathrm{ET}_{0}$ of P-M with other 6 models. If results perfectly predicted the data, observed-versus-predicted points would lie on line $\mathrm{x}=\mathrm{y}$. Evaluation parameters, root mean square error (RMSE) and Nash-Sutcliffe coefficient $\left(\mathrm{C}_{\mathrm{D}}\right)$, were used to characterize the deviation of the calculated values form the results of P-M method. The tow equations are: 


$$
R M S E=\sqrt{\frac{\sum_{i=1}^{n}\left(E T_{0}{ }^{\prime}-E T_{0-P M}\right)^{2}}{n-1}}, \quad C_{D}=1-\frac{\sum_{t=1}^{n}\left(E T_{0}{ }^{\prime}-E T_{0-P M}\right)^{2}}{\sum_{t=1}^{n}\left(E T_{0-P M}-\overline{E T_{0-P M}}\right)^{2}}
$$

Where, $\mathrm{n}$, the sample number; $\mathrm{ET}_{0}{ }^{\prime}, \mathrm{ET}_{0}$ of each method(mm/d); $\mathrm{ET}_{0-\mathrm{PM}}$, daily $\mathrm{ET}_{0}$ calculated by $\mathrm{P}-\mathrm{M} \operatorname{method}(\mathrm{mm} / \mathrm{d}) ; \overline{\mathrm{ET}_{0-\mathrm{PM}}}$, the average of daily $\mathrm{ET}_{0}$ calculated by P-M method(mm/d).

\section{Scores of the Methods}

Evaluating the goodness-of-fit of 6 models firstly, and then defining 6 degrees: best, better, good, normal, poor, poorer. The goodness-of-fit scores were 3, 2, 1, 0, -1 and -2 in turn. The models were compared from 3 evaluative aspects: the goodness-of-fit, definition and the applicability of monthly average $\mathrm{ET}_{0}$ accumulated values. First, the 6 methods were rank from best to poorer, then the 6 algorithm got corresponding scores. Ultimately, according the total scores they got from 3 evaluative aspects, the different goodness-of-fit of 6 models was showed out in Hebei Provence.

\section{Result and Analysis}

Goodness-of-fit of Methods (1): the equation in goodness-of-fit and determination coefficient between 6 methods and P-M are listed in sheet-1. In Part 1, algorithms' gradients(K) of M-K and PVB were 1.247 and 1.036, and $\mathrm{ET}_{0-\mathrm{MK}}$ and $\mathrm{ET}_{0-\mathrm{PVB}}$ were bigger than $\mathrm{ET}_{\mathrm{PM}} ; \mathrm{ET}_{0-\mathrm{HS}}, \mathrm{ET}_{0-\mathrm{IA}}, \mathrm{ET}_{0-\mathrm{PT}}$ and $\mathrm{ET}_{0-48 \mathrm{PM}}$ were lower $(0.797,0.98,0.921,0.849)$. The $\mathrm{K}$ of PVB and I-A were closer to 1 showing better applicability. In Part 2, except the M-K (bigger than P-M), other 5 methods were lower, and K of PVB and I-A $(0.979,0.879)$ were more close to 1 ; the $\mathrm{K}$ of $\mathrm{H}-\mathrm{S}$ was the smallest $(0.718)$. In Part 3, $\mathrm{ET}_{0-\mathrm{MK}}$ and $\mathrm{ET}_{0-\mathrm{PVB}}$ were bigger than $\mathrm{ET}_{0-\mathrm{PM}}$, with the $\mathrm{K} 1.233$ and 1.086; $\mathrm{ET}_{0-\mathrm{HS}}, \mathrm{ET}_{0-\mathrm{IA}}, \mathrm{ET}_{0-\mathrm{PT}}$ and $\mathrm{ET}_{0-48 \mathrm{PM}},(0.786,0.959,0.935,0.845)$, were smaller than $\mathrm{ET}_{\mathrm{PM}}$. I-A and P-T method were close to1. The applicability of I-A and P-T method were better while H-S method was the worst. Every algorithm's coefficient of determination was bigger than $65 \%$.

Table1 Imitative equation and determination coefficient between $6 \mathrm{ET}_{0}$ methods and P-M in Hebei Provence

\begin{tabular}{ccccccc}
\hline Method & $\mathrm{H}-\mathrm{S}$ & $\mathrm{I}-\mathrm{A}$ & $\mathrm{P}-\mathrm{T}$ & $\mathrm{M}-\mathrm{K}$ & $48-\mathrm{PM}$ & $\mathrm{PVB}$ \\
\hline \multirow{2}{*}{ Part 1 } & $\mathrm{y}=0.797 \mathrm{x}+0.29 \mathrm{y}=0.986 \mathrm{x}-0.25 \mathrm{y}=0.921 \mathrm{x}+0.67 \mathrm{y}=1.247 \mathrm{x}+0.28 \mathrm{y}=0.849 \mathrm{x}-0.12 \mathrm{y}=1.036 \mathrm{x}+0.55$ \\
& $\mathrm{R}^{2}=0.8018$ & $\mathrm{R}^{2}=0.7828$ & $\mathrm{R}^{2}=0.7852$ & $\mathrm{R}^{2}=0.8522$ & $\mathrm{R}^{2}=0.9958$ & $\mathrm{R}^{2}=0.7858$ \\
Part 2 & $\mathrm{y}=0.718 \mathrm{x}-0.90 \mathrm{y}=0.879 \mathrm{x}+0.42 \mathrm{y}=0.860 \mathrm{x}+1.16 \mathrm{y}=1.182 \mathrm{x}+0.65 \mathrm{y}=0.826 \mathrm{x}-0.12 \mathrm{y}=0.979 \mathrm{x}+1.02$ \\
& $\mathrm{R}^{2}=0.7609$ & $\mathrm{R}^{2}=0.6956$ & $\mathrm{R}^{2}=0.6970$ & $\mathrm{R}^{2}=0.7818$ & $\mathrm{R}^{2}=0.9810$ & $\mathrm{R}^{2}=0.6916$ \\
Part 3 & $\mathrm{y}=0.786 \mathrm{x}+0.75 \mathrm{y}=0.959 \mathrm{x}+0.26 \mathrm{y}=0.935 \mathrm{x}+1.03$ & $\mathrm{y}=1.233 \mathrm{x}+0.57 \mathrm{y}=0.845 \mathrm{x}-0.11 \mathrm{y}=1.086 \mathrm{x}+0.88$ \\
& $\mathrm{R}^{2}=0.7934$ & $\mathrm{R}^{2}=0.7600$ & $\mathrm{R}^{2}=0.7629$ & $\mathrm{R}^{2}=0.8341$ & $\mathrm{R}^{2}=0.9918$ & $\mathrm{R}^{2}=0.7548$ \\
\hline
\end{tabular}

Definition of the Methods (2): RMSE and $C_{D}$ of 6 methods are listed in sheet-2. In Part 1, RMSE and $C_{D}$ of PVB and M-K were $1.3553 \mathrm{~mm} / \mathrm{d}, 0.6523$ and $1.2743 \mathrm{~mm} / \mathrm{d}, 0.6270 ;$ RMSE of PVB was the biggest while $\mathrm{C}_{\mathrm{D}}$ of M-K was the smallest; deviation of PVB was bigger. RMSE of P-T, H-S, I-A and 48-PM decreased while $\mathrm{C}_{\mathrm{D}}$ increased; the precision of these increased in turn. In Part 2, RMSE and $\mathrm{C}_{\mathrm{D}}$ of PVB were $1.3692 \mathrm{~mm} / \mathrm{d}$ and 0.3768 . RMSE of PVB was biggest while $\mathrm{C}_{\mathrm{D}}$ was smallest. RMSE of P-T, H-S, I-A and 48-PM decreased while $\mathrm{C}_{\mathrm{D}}$ increased. The precision of algorithms in Part 3 was the same with that in Part 1; the precision of PVB, M-K, P-T, H-S, I-A and 48-PM increased in turn.

Table2 Comparison $\mathrm{ET}_{0}$ accuracy among 6 simplification calculations and P-M in 3 divisions in Hebei Provence

\begin{tabular}{cccccccc}
\hline \multicolumn{2}{c}{ Evaluation Parameter } & H-S & I-A & P-T & M-K & 48-PM & PVB \\
\hline Part 1 & RMSE & 0.9141 & 0.8706 & 1.2424 & 1.2743 & 0.7498 & 1.3553 \\
\hline
\end{tabular}




\begin{tabular}{lccccccc}
\hline \multirow{4}{*}{} & $(\mathrm{mm} / \mathrm{d})$ & & & & & & \\
& $\mathrm{C}_{\mathrm{D}}$ & 0.7161 & 0.7537 & 0.6961 & 0.6270 & 0.8381 & 0.6523 \\
Part 2 & $\mathrm{RMSE}$ & 1.1095 & 0.9805 & 1.3140 & 1.3107 & 0.8816 & 1.3692 \\
& $(\mathrm{~mm} / \mathrm{d})$ & & & & & & \\
& $\mathrm{C}_{\mathrm{D}}$ & 0.5909 & 0.6805 & 0.4261 & 0.4290 & 0.7417 & 0.3768 \\
\multirow{2}{*}{ Part 3 } & $\mathrm{RMSE}$ & 0.9086 & 0.8654 & 1.2349 & 1.2667 & 0.7453 & 1.3472 \\
& $(\mathrm{~mm} / \mathrm{d})$ & & & & & & \\
& $\mathrm{C}_{\mathrm{D}}$ & 0.7302 & 0.7552 & 0.5016 & 0.4756 & 0.8185 & 0.4069 \\
\hline
\end{tabular}

Applicability of Monthly Average ET0 Accumulated Values of the Methods (3): monthly average $\mathrm{ET}_{0}$ accumulated values of P-M method in Part 1, Part 2, Part 3 and Hebei were $867.55 \mathrm{~mm}$, $954.80 \mathrm{~mm}, 931.78 \mathrm{~mm}$ and $918.04 \mathrm{~mm}$. As Figure 2 shows: the values of I-A, H-S and 48-PM were higher than P-M in Part 1, and their deviation values were $95.24 \mathrm{~mm}, 103.10 \mathrm{~mm}$ and $199.00 \mathrm{~mm}$ while the values of P-T, PVB and $\mathrm{M}-\mathrm{K}$ were lower than P-M, and their deviation values were $161.67 \mathrm{~mm}, 203.91 \mathrm{~mm}$ and $245.22 \mathrm{~mm}$. In Part 2, the value of 48-PM was higher than P-M in excess of $248.36 \mathrm{~mm}$ while the values of I-A, H-S, P-T, PVB and M-K were lower than P-M, and their deviation values were $25.07 \mathrm{~mm}, 26.88 \mathrm{~mm}, 281.83 \mathrm{~mm}, 316.87 \mathrm{~mm}$ and $324.43 \mathrm{~mm}$. In Part 3 , the value of 48-PM was higher than P-M in excess of $211.99 \mathrm{~mm}$; the values of I-A, H-S, P-T, M-K and PVB were lower than P-M, and the deviation values were $45.63 \mathrm{~mm}, 49.65 \mathrm{~mm}, 288.76 \mathrm{~mm}$, $325.43 \mathrm{~mm}$ and $332.83 \mathrm{~mm}$. In Hebei the values of I-A, H-S and 48-PM were higher than P-M in excess of $8.18 \mathrm{~mm}, 8.86 \mathrm{~mm}$ and $219.78 \mathrm{~mm}$, while the values by P-T, PVB and M-K method were lower than P-M and the deviation values were $244.09 \mathrm{~mm}, 284.54 \mathrm{~mm}$ and $298.36 \mathrm{~mm}$.

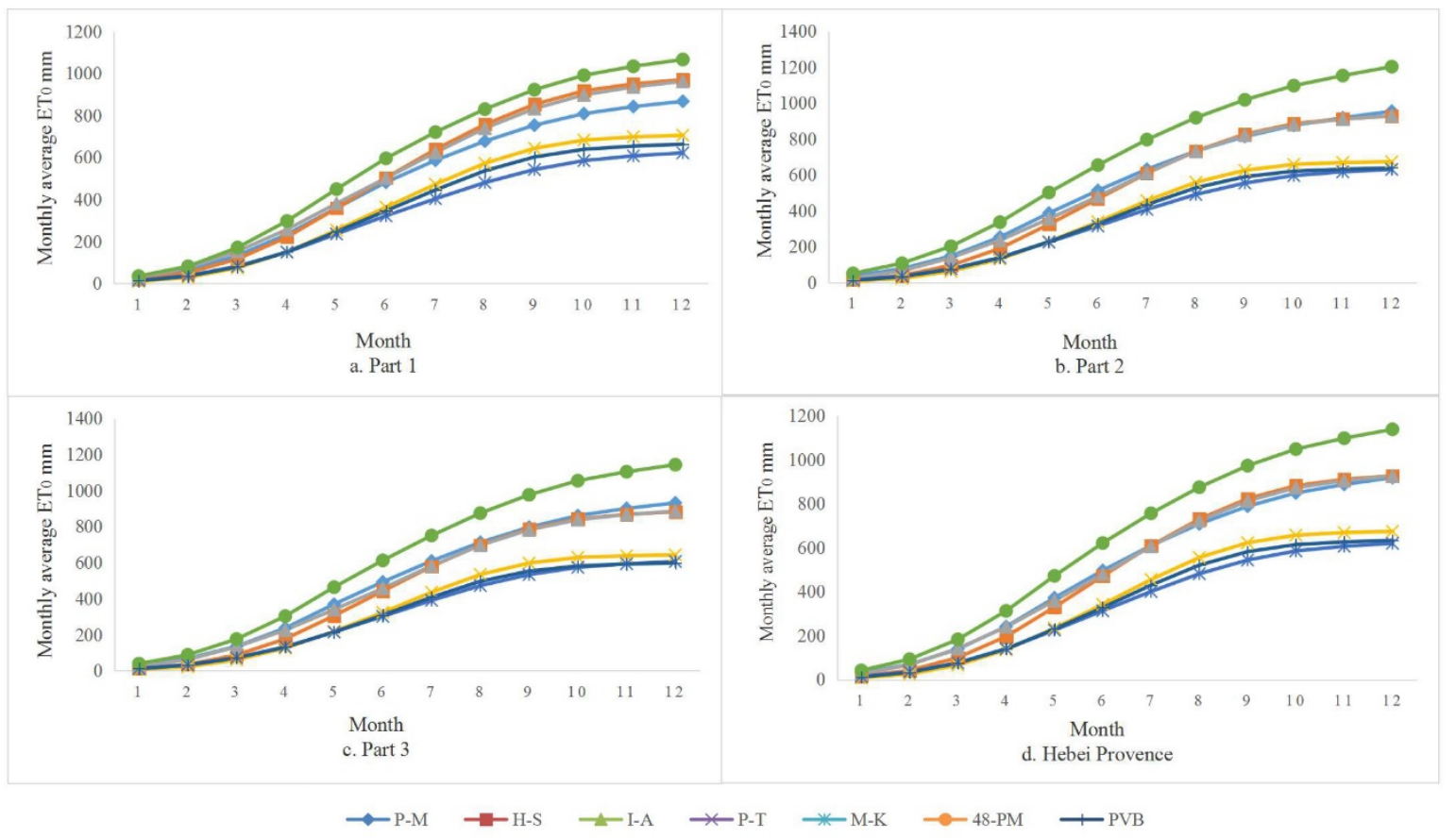

Fig.2 Monthly average $\mathrm{ET}_{0}$ accumulated values comparison among 6 simplification calculations

Table. 33 evaluative aspects scores of 6 simplification calculations in 3 divisions

\begin{tabular}{cccccccc}
\hline Part & evaluative aspect & H-S & I-A & P-T & M-K & $48-P M$ & PVB \\
\hline \multirow{4}{*}{1} & $(1)$ & -1 & 3 & 1 & -2 & 0 & 2 \\
& $(2)$ & 1 & 2 & 0 & -1 & 3 & -2 \\
& $(3)$ & 2 & 3 & 1 & -2 & 0 & -1 \\
2 & 1 & -2 & 2 & 1 & -1 & 0 & 3 \\
& $(2)$ & 1 & 2 & -1 & 0 & 3 & -2 \\
\hline
\end{tabular}




\begin{tabular}{cccccccc}
\hline & $(3)$ & 2 & 3 & 0 & -2 & 1 & -1 \\
& 1 & -1 & 3 & 2 & -2 & 0 & 1 \\
3 & $(2)$ & 1 & 2 & 0 & -1 & 3 & -2 \\
& $(3$ & 2 & 3 & 0 & -1 & 1 & -2 \\
total & & 5 & 23 & 4 & -12 & 11 & -4 \\
\hline
\end{tabular}

\section{the Scores of Methods}

According to the analyses of 3 evaluative aspects in the 3 divisions, the scores of 6 simplification calculations were showed in table 3. It showed: the scores of M-K, PVB, P-T, H-S, 48-PM and I-A method were $-12,-4,4,5,11$ and 23 respectively indicating that taking the P-M method as the standard, I-A method was the best fit one among the 6 methods considering the goodness-of-fit, definition and the applicability of monthly average $\mathrm{ET}_{0}$ accumulated values; the accuracy and applicability of I-A method was higher than any other methods; 48-PM method was the second; M-K method was for the worse grade, and only scored -12 points.

\section{Conclusions}

The conclusions are as follows: (1) I-A and PVB were better than others in the goodness-of-fit; (2) I-A and 48-PM were better when analyzing the RMSE and CD; (3) I-A and H-S were better in the 3 divisions when analyzing monthly average $\mathrm{ET}_{0}$ accumulated values; (4) the applicability of I-A was the best among 6 methods with the highest score; 48-PM ranked second and M-K was the last; (5) the scoring method was reasonable in estimating the applicability of methods, and it got the same conclusion compared with qualitative analysis; and the scoring mechanism for this method would be more consummate in subsequent studies.

\section{References}

[1] Shaozhong Kang. Agrieultural Water and Soil Engineering[M]. China Agriculture Press, Beijing, 2005. (in Chinese)

[2] Shanqing Zhang, Zongchao Pu, Liangluan Song, et al. Effect of climate change on potential Evapotiration in Turpan Region[J]. Chinese Journal of Agrometeorlogy,2009,30(4):532-537. (in Chinese)

[3] Yonghong Duan, Shu Tao, Bengang Li. Spatial and temporal variation of reference crop evapotranspiration in Beijing [J]. Chinese Journal of Agrometeorlogy,2004,25(2) : 22-25. (in Chinese)

[4] Junzeng $\mathrm{Xu}$, Shizhang Peng, Jiali Ding, et al. Evaluation of methods for estimating daily reference crop evapotranspiration based on lysimeter grass experiments[J]. Journal of Hydraulic Engineering, 2010,41(12):1497-1505. (in Chinese)

[5] Xystrakis F, Matzarakis A. Evaluation of 13 empirical reference potential evapotranspiration equations on the island of Crete in southern Greece[J]. Journal of Irrigation and Drainage Engineering, 2010,137(4):211-222.

[6] Azhar A H, Perera B J C. Evaluation of reference evapotranspiration estimation methods under Southeast Australian conditions[J]. Journal of Irrigation and Drainage Engineering, 2010,137(5):268-279.

[7] Qingyu Sun, Ling Tong, Baozhong Zhang, et al. Comparison of methods for calculating reference crop evapotranspiration in Haihe River basin of China[J]. Transactions of the Chinese 
Society of Agricultural Engineering (Transactions of the CSAE), 2010,26(11):68-72. (in Chinese)

[8] Zhi Li. Applicability of simple estimating method for reference crop evapotranspiration in Loess Plateau[J]. Transactions of the Chinese Society of Agricultural Engineering (Transactions of the CSAE), 2012,28(6):106-111. (in Chinese)

[9] Hargreaves G H, Allen R G. History and evaluation of Hargreaves evapotranspiration equation[J]. Journal of Irrigation and Drainage Engineering, 2003,129(1):53-63. (in Chinese)

[10]Lu Zhao, Chuan Liang, Ningbo Cui, et al. Comparison and improvement of different calculation methods for $\mathrm{ET}_{0}$ in hillyarea of agricultural engineering (Transactions of the CSAE), 2012,28(24):92-98. (in Chinese)

[11]Penman H L. Natural evaporation from open water, bare soil grass[C]. Proceedings of the Royal Society of London A:Mathematical, Physical and Engineering Sciences. The Royal Society, 1948,193(1032):120-145.

[12]Van Bavel C H M. Potential evapotranspiration: the combination concept and its experimental verification[J]. Water Resources Research, 1996,2(3):23-34. 